\title{
HUBUNGAN ANTARA PANJANG TUNGKAI, KOORDINASI MATA- KAKI, DAN POWER OTOT TUNGKAI DENGAN KETEPATAN SHOOTING SEPAKBOLA PADA PEMAIN PUTRA UMUR 14-15 TAHUN KLUB SSB UTP SURAKARTA TAHUN 2020
}

\section{Oleh Feri Fitriyanto}

\begin{abstract}
ABSTRAK
Tujuan dari penelitian ini adalah untuk mengetahui: (1) Hubungan Antara Panjang Tungkai dengan Ketepatan Shooting Sepakbolapada Pemain Putra Umur 14-15 Tahun Klub SSB UTP Surakarta Tahun 2020. (2) Hubungan Antara Koordinasi Mata-Kaki dengan Ketepatan Shooting Sepakbola pada Pemain Putra Umur 14-15 Tahun Klub SSB UTP Surakarta Tahun 2020. (3) Hubungan Antara Power Otot Tungkai dengan Ketepatan Shooting Sepakbola pada Pemain Putra Umur 14-15 Tahun Klub SSB UTP Surakarta Tahun 2020. (4) Hubungan Antara Panjang Tungkai, Koordinasi Mata-Kaki dan Power Otot Tungkai dengan Ketepatan Shooting Sepakbola pada Pemain Putra Umur 14-15 Tahun Klub SSB UTP Surakarta Tahun 2020.

Penelitian ini dilaksanakan di SSB UTP Surakarta dan penelitian ini dilaksanakan pada bulan September tahun 2020. Dalam penelitian ini variabel bebas disebut juga sebagai prediktor dan variabel terikat yang disebut juga sebagai kriterium. Teknik pengumpulan data dalam penelitian ini adalah menggunakan teknik tes dan pengukuran. Adapun jenis tes yang digunakan adalah: (1) Tes dan pengukuranpanjang tungkai untuk mengukur panjang tungkai (Ismaryati, 2008:100). (2) Tes dan pengukuran koordinasi mata kaki dengan soccer wall voley test (Ismaryati, 2011: 54-56).(3) Tes dan pengukuran power otot tungkai dengan standing broad jump test (Ismaryati, 2008: 64). (4)Tes dan pengukuran ketepatan shooting bola menggunakan petunjuk tes shooting bola ke gawang (Sukatamsi, 1984: 277-278).Petunjuk pelaksanaan masing-masing tes terlampir.
\end{abstract}

Berdasarkan analisis data dan pengujian hipotesis yang telah dilakukan, maka simpulan yang dapat diperoleh adalah: (1) Ada hubungan yang signifikanantara Panjang Tungkai dengan Ketepatan shooting, $\mathrm{r}_{\text {hitung }}=0.459>$ $\mathrm{r}_{\text {tabel }} 5 \%=0,361$. (2) Ada hubungan yang signifikan antara Koordinasi mata kakidengan Ketepatan shooting, $r_{\text {hitung }}=0.423>r_{\text {tabel }} 5 \%=0,361$. (3) Ada hubungan yang signifikan antara Power otot tungkai dengan Ketepatan shooting, $r_{\text {hitung }}=0.403>r_{\text {tabel }} \%=0,361$. (4) Ada hubungan yang signifikan antara Panjang Tungkai, Koordinasi mata kaki dan Power otot tungkai dengan Ketepatan shooting, $\mathrm{R}_{\mathrm{y}(123)}^{2}$ sebesar $0.411>\mathrm{r}_{\text {tabel5 } \%}$ pada taraf signifikansi $5 \%$ sebesar 0.361 dan $F_{0}$ sebesar $6.0494>f_{\text {tabel }}$ pada taraf signifikansi 5\% sebesar 2,89.

Kata Kunci :Panjang Tungkai, Koordinasi Mata-Kaki, Power Otot Tungkai Ketepatan Shooting 


\section{A. PENDAhuluan}

Perkembangan transfer pemain kelas dunia sangat tidak masuk diakal. Ini seiring dengan kemampuan individu yang diatas rata-rata yang memaksimalkan kerjasama tim menjadi sebuah kemenangan. Perkembangan ini juga diiringi dengan kualitas teknik dan taktik permainan sepakbola yang terus semakin berkembang. Untuk olahraga yang bertujuan mencapai prestasi yang maksimal, seseorang dituntut harus menguasai teknik-teknik dasar, taktik dan mental bertanding serta memiliki kemampuan kondisi fisik yang baik.

Terlebih lagi saat ini seorang pemain benarา-benar dituntut untuk mengikuti perkembangan permainan sepakbola mutakhir dengan ditunjang kemampuan fisik yang baik, agar mereka mampu bermain selama pertandingan secara penuh. Oleh karena itu seorang pemain dituntut untuk melakukan latihan kondisi fisik dengan baik dan benar. Sepakbola merupakan permainan beregu, masing-masing regu terdiri dari sebelas orang, dan salah satunya penjaga gawang. Dalam permainan sepakbola ada berbagai teknik yang digunakan seperti, drible, passing, control, shooting, dan heading. Begitu banyaknya aspek manfaat yang ada dalam sepakbola baik faktor financial atau faktor yang lain. Permainan sepakbola sendiri mempunyai tujuan untuk masing-masing regu atau kesebelasan berusaha menguasai bola, memasukkan bola kedalam gawang lawan sebanyak mungkin dan berusaha mematahkan serangan lawan untuk melindungi atau menjaga gawangnya agar tidak kemasukan bola. Dari penjelasan tersebut dapat diketahuibahwa tujuan sepakbola adalah untuk mencetak angka atau gol. Untuk mencetak angka atau gol memerlukan teknik dasar yang disebut dengan shooting.

Tujuan dari shooting adalah untuk memasukkan bola ke gawang lawan dengan tujuan untuk memperoleh poin untuk merubah keadaan yang sering disebut dengan skor. Dengan demikian bagian tubuh yang berperan untuk melakukan shooting adalah kaki. Kekuatan tungkai merupakan salah 
satu yang memegang peranan yang penting dalam keberhasilan shooting bola ke gawang. Pemain sepakbola sangat penting sekali menguasai skill individu dalam permainan sepakbola. Dengan latihan skill dan kondisi fisik yang dimiliki setiap pemain, akan memiliki tendangan yang keras dengan akurasi tendangan yang bisa mendekati maksimal. Semakin banyak skor yang diperoleh maka akan semakin besar pula peluang kemenangan yang akan diperoleh suatu tim.

Teknik yang buruk dalam melakukan shooting sering menyebabkan peluang mencetak gol menjadi terlewatkan. Di level dunia pun banyak pemain melakukan shooting yang terlalu tinggi, melebar, atau bahkan ragu-ragu dalam melakukan nya. Dengan demikian, kegagalan melakukan shooting juga berarti kegagalan mencetak angka atau gol. Tiap pemain mempunyai fungsi yang berbeda-beda yaitu penyerang atau pemain depan berfungsi sebagai penyerang, oleh karena itu seorang pemain depan dituntut untuk dapat mencetak gol ke gawang lawan. Kemudian pemain tengah atau gelandang berfungsi sebagai pengumpan bola atau bisa juga gelandang bertugas membantu penyerang untuk memasukan bola ke gawang. Dengan demikian banyak pelatih-pelatih memaksimalkan shooting untuk mencapai kemenangan dalam pertandingan.

Di SSB UTP Surakarta sudah menerima siswa sejak usai dini sebagai penampung bibit-bibit pemain sepakbola dan langsung diberikan materi dasar sepakbola yang diberikan 3 kali dalam seminggu. Sehingga dapat dikatakan, siswa putra usia 14-15 Tahun tersebut yang terpilih menjadi sample penelitian, sudah dapat melakukan keterampilan teknik sepakbola salah satunya adalah teknik shooting atau dengan kata lain teknik shooting sudah dapat dikuasai dengan baik. Hal inilah yang kemudian membuat peneliti tertarik untuk mengadakan penelitian yakni jenis penelitian korelasional. Maksudnya adalah peneliti tertarik mengadakan penelitian mengenai teknik shooting yang telah dikuasai oleh 
para siswa putra usia 12 tahun tersebut dengan menghubungkan unsurunsur kondisi fisik yang mendukung didalam proses pelaksanaan teknik keterampilan gerakan shooting.

Berdasarkan pengamatan peneliti, teknik keterampilan shooting dapat dilakukan dengan baik, apabila para pemain mempunyai bekal power otot tungkai yang baik. Oleh karena di dalam melakukan teknik shooting dalam permainan sepakbola, pemain harus menendang bola ke sasaran dengan kuat, agar dalam beraksi tersebut dapat berhasil dengan baik maka para pemain yang mau melakukan teknik tersebut harus menggunakan anggota tubuhnya dengan kelentukan yang baik terutama untuk melakukan gerak tipu. Dalam pelaksanaan tersebut, para pemain juga harus memperhatikan keras lunaknya bola, tebal tipisnya rumput, sehingga membantu pemain dalam menentukan putusan arah shooting, dengan salah satu faktor pembantu keberhasilan shooting yaitu panjang tungkai.

Pemain SSB UTP Surakarta pada umumnya yang belum menguasai teknik ketepatan shooting bola, merasa belum siap bahkan belum memiliki kekuatan yang memadai, sehingga mengalami kesulitan untuk melakukan ketepatan shooting bola. Kurangnya sarana yang kurang efektif merupakan faktor yang dapat mempengaruhi rendahnya peningkatan ketepatan shooting bola. Selain itu, jarang sekali seorang pelatih maupun pembina menciptakan variasi-variasi latihan yang disesuaikan dengan kondisi dan kemampuan pemainnya. Hal ini sangat penting untuk diperhatikan dalam latihan keterampilan terutama untuk pemain pemula. Kondisi yang tidak memungkinkan untuk latihan dengan sarana yang ada, menuntut pelatih maupun pembina berkreativitas agar tujuan latihan dapat tercapai dengan baik.

Perbedaan kemampuan terutama terjadi karena kualitas fisik yang berbeda (Sugiyanto, 2009: 15) bahwa kemampuan fisik adalah bagian esensial landasan 
untuk perkembangan gerakan-gerakan yang terampil.. Begitu juga dengan power otot tungkai yang mempengaruhi keterampilan pemain. Dengan demikian dapat dikatakan power otot tungkai, dan koordinasi mata kaki adalah suatu persyaratan dalam usaha mencapai prestasi maksimal bagi seseorang dalam latihan ketepatan shooting bola. Power otot tungkai, dan koordinasi mata kaki yang ada pada pemain putra harus menjadi pertimbangan sebagai suatu faktor yang menentukan dalam ketepatan shooting bola yang sesuai dengan karakter dari masing-masing pemain sehingga bisa mencapai hasil latihan yang optimal sesuai dengan potensi yang dimiliki.

\section{B. METODE PENELITIAN \\ C. Metode penelitian yang digunakan adalah metode deskriptif studi korelasional. Dalam hal ini Ali Maksum (2012: 68) berpendapat bahwa "melalui studi korelasional dapat diketahui apakah satu variabel berasosiasi dengan variabel yang lain. Hubungan antara variabel ditentukan dengan menggunakan koefisien yang dihitung dengan teknik analisis statistik". Penelitian ini untuk mengetahui hubungan antara panjang tungkai, koordinasi mata-kaki dan power otot tungkaidengan ketepatanShooting bola}

\section{HASIL PENELITIAN}

\section{A. Deskripsi Data}

Data yang diperoleh dari tiap-tiap variabel tersebut kemudian dikelompokkan dan dianalisis dengan statistik, seperti terlihat pada lampiran. Adapun rangkuman deskripsi data secara keseluruhan akan disajikan sebagai berikut: 
Hubungan Antara Panjang Tungkai, Koordinasi Mata-Kaki, Dan Power Otot Tungkai Dengan Ketepatan Shooting Sepakbola Pada Pemain Putra Umur 14-15 Tahun Klub Ssb UTP Surakarta Tahun 2020

(Feri Fitrianto)

Tabel 1.Deskripsi Data Hasil Tes Panjang Tungkai , Koordinasi mata kaki dan Power otot tungkai dan Ketepatan shooting .

\begin{tabular}{|c|c|c|c|c|c|c|}
\hline Variabel & Tes & $\mathrm{N}$ & Mean & SD & $\begin{array}{c}\text { Nilai } \\
\text { Tertinggi }\end{array}$ & $\begin{array}{c}\text { Nilai } \\
\text { Terendah }\end{array}$ \\
\hline \multirow{2}{*}{ Panjang Tungkai } & Test & 30 & 62.87 & 5.96 & 76 & 55 \\
\cline { 2 - 7 } & Re-test & 30 & 62.87 & 5.96 & 76 & 55 \\
\hline $\begin{array}{c}\text { Koordinasi mata } \\
\text { kaki }\end{array}$ & Test & 30 & 13.93 & 1.55 & 16 & 11 \\
\cline { 2 - 7 } & Re-test & 30 & 14.83 & 1.64 & 18 & 12 \\
\hline \multirow{2}{*}{\begin{tabular}{c} 
Power otot tungkai \\
\cline { 2 - 7 } Ketepatan shooting
\end{tabular}} & Test & 30 & 185.67 & 22.66 & 225 & 140 \\
\cline { 2 - 7 } & Re-test & 30 & 189.67 & 19.56 & 225 & 155 \\
\hline & Re-test & 30 & 68.50 & 13.14 & 95 & 50 \\
\hline
\end{tabular}

\section{B. Uji Reliabilitas}

Uji reliabilitas bertujuan untuk mengetahui tingkat keajegan hasil tes masing-masing variabel yang dilakukan dalam penelitian. Hasil uji reliabilitas tes dan re-testPanjang Tungkai, Koordinasi mata kaki dan Power otot tungkai dan Ketepatan shooting kemudian dikategorikan, dengan menggunakan pedoman tabel koefisien korelasi dari Book Walter yang dikutip Mulyono BiyaktoAtmojo (2008:22), yaitu:

Tabel 2. Range Kategori Reliabilitas

\begin{tabular}{|c|c|}
\hline Kategori & Reliabilitas \\
\hline Tinggi Sekali & $0,90-1,00$ \\
\hline Tinggi & $0,80-0,89$ \\
\hline Cukup & $0,60-0,79$ \\
\hline Kurang & $0,40-0,59$ \\
\hline Tidak Signifikan & $0,00-0,39$ \\
\hline
\end{tabular}

Hasil uji reliabilitas data Panjang Tungkai, Koordinasi mata kaki dan 
Hubungan Antara Panjang Tungkai, Koordinasi Mata-Kaki, Dan Power Otot Tungkai Dengan Ketepatan Shooting Sepakbola Pada Pemain Putra Umur 14-15 Tahun Klub Ssb UTP Surakarta Tahun 2020

(Feri Fitrianto)

Power otot tungkai dan Ketepatan shooting pada penelitian ini adalah:

Tabel 3. Ringkasan Hasil Uji Reliabilitas Data

\begin{tabular}{|l|c|c|}
\hline \multicolumn{1}{|c|}{ Variabel } & Reliabilita & Kategori \\
\hline Panjang Tungkai & 1.000 & Tinggi Sekali \\
\hline Koordinasi mata kaki & 0.943 & Tinggi Sekali \\
\hline Power otot tungkai & 0.944 & Tinggi Sekali \\
\hline Ketepatan shooting & 0.714 & Cukup \\
\hline
\end{tabular}

\section{Pengujian Persyaratan Analisis}

Sebelum analisis data dilakukan uji persyaratan analisis. Untuk analisis regresi diperlukan uji persyaratan analisis yaitu normalitas penyebarannilai dan persyaratan linieritas hubungan antara prediktor dengan kriterium. Hasil pengujian persyaratan analisis pada penelitian ini adalah sebagai berikut:

\section{Uji Normalitas}

Uji normalitas data dalam penelitian ini menggunakan chi-kuadrat. Adapun hasil uji normalitas yang dilPower otot tungkaikan pada hasil tes Panjang Tungkai $\left(\mathrm{X}_{1}\right)$, Koordinasi mata kaki $\left(\mathrm{X}_{2}\right)$, Power otot tungkai $\left(\mathrm{X}_{3}\right)$ dan Ketepatan shooting (Y) pada penelitian ini adalah:

Tabel 4. Rangkuman Hasil Uji Normalitas Data

\begin{tabular}{|l|c|c|c|c|c|c|}
\hline \multicolumn{1}{|c|}{ Variabel } & $\mathrm{Db}$ & $\mathrm{M}$ & $\mathrm{SD}$ & $\chi_{\text {hitung }}^{2}$ & $\chi_{\text {tabel } 5 \%}^{2}$ & Simpulan \\
\hline $\begin{array}{l}\text { Panjang } \\
\text { Tungkai }\end{array}$ & $\begin{array}{c}6-1 \\
=5\end{array}$ & 62.87 & 5.96 & 2.358 & 11,070 & $\begin{array}{c}\text { Berdistribusi } \\
\text { normal }\end{array}$ \\
\hline $\begin{array}{l}\text { Koordinasi } \\
\text { mata kaki }\end{array}$ & $\begin{array}{c}6-1 \\
=5\end{array}$ & 13.93 & 1.55 & 2.358 & 11,070 & $\begin{array}{c}\text { Berdistribusi } \\
\text { normal }\end{array}$ \\
\hline $\begin{array}{l}\text { Power otot } \\
\text { tungkai }\end{array}$ & $\begin{array}{c}6-1 \\
=5\end{array}$ & 185.67 & 22.66 & 1.667 & 11,070 & $\begin{array}{c}\text { Berdistribusi } \\
\text { normal }\end{array}$ \\
\hline $\begin{array}{l}\text { Ketepatan } \\
\text { shooting }\end{array}$ & $\begin{array}{c}6-1 \\
=5\end{array}$ & 55.67 & 12.98 & 2.167 & 11,070 & $\begin{array}{c}\text { Berdistribusi } \\
\text { normal }\end{array}$ \\
\hline
\end{tabular}


Dari hasil uji normalitas yang dilakukan pada tiap-tiap variabel tersebut dapat diketahui bahwa nilai chi-kuadrat yang diperoleh $\left(\chi^{2}\right.$ hitung $)$ pada variabel Panjang Tungkai $\left(\mathrm{X}_{1}\right)$, Koordinasi mata kaki $\left(\mathrm{X}_{2}\right)$, Power otot tungkai $\left(\mathrm{X}_{3}\right)$ dan Ketepatan shooting $(\mathrm{Y})$ lebih kecil dari nilai chi-kuadrat dalam tabel $\left(\chi_{\text {tabel }}^{2} \%\right)$. Dengan demikian hipotesis nol diterima. Yang berarti bahwa data hasil tes Panjang Tungkai $\left(\mathrm{X}_{1}\right)$, Koordinasi mata kaki $\left(\mathrm{X}_{2}\right)$, Power otot tungkai $\left(\mathrm{X}_{3}\right)$ dan Ketepatan shooting (Y) termasuk berdistribusi normal.

\section{Uji Linieritas}

Uji linieritas hubungan antara masing-masing prediktor yaitu Panjang Tungkai $\left(\mathrm{X}_{1}\right)$, Koordinasi mata kaki $\left(\mathrm{X}_{2}\right)$, Power otot tungkai $\left(\mathrm{X}_{3}\right)$, dengan kriterium yaitu Ketepatan shooting (Y) dilakukan dengan analisis varians. Rangkuman hasil uji linieritas tersebut dapat dilihat dalam tabel sebagai berikut:

Tabel 5. Rangkuman Hasil Analisis Varians Untuk Uji Linieritas Hubungan Antara Prediktor dengan Kriterium

\begin{tabular}{|c|c|c|c|c|}
\hline Variabel & $\mathrm{db}$ & $\mathrm{F}_{\text {hitung }}$ & $\mathrm{F}_{\text {tabel5\% }}$ & Simpulan \\
\hline $\mathrm{X}_{1} \mathrm{Y}$ & $4: 24$ & 0.14 & 2,78 & Model linier diterima \\
\hline $\mathrm{X}_{2} \mathrm{Y}$ & $13: 15$ & 0.48 & 2,43 & Model linier diterima \\
\hline $\mathrm{X}_{3} \mathrm{Y}$ & $20: 8$ & 0.73 & 3,15 & Model linier diterima \\
\hline
\end{tabular}

Dari rangkuman hasil uji linieritas tersebut dapat diketahui bahwa nilai $F_{\text {hitung }}$ linieritas yang diperoleh dari tiap variabel lebih kecil dari harga $\mathrm{F}_{\text {tabel }}$ 5\%. Dengan demikian hipotesis nol linieritas ketiga variabel tersebut diterima. Berarti bahwa baik korelasi antara $\mathrm{X}_{1} \mathrm{Y}, \mathrm{X}_{2} \mathrm{Y}$ dan $\mathrm{X}_{3} \mathrm{Y}$ berbentuk linier.

\section{Hasil Analisis Data}

Hasil analisis korelasi dan analisis regresi antara data tes Panjang Tungkai $\left(\mathrm{X}_{1}\right)$, Koordinasi mata kaki $\left(\mathrm{X}_{2}\right)$, Power otot tungkai $\left(\mathrm{X}_{3}\right)$ dengan Ketepatan shooting (Y) penelitian ini adalah: 


\section{Analisis Korelasi Tiap Prediktor}

Hasil analisis korelasi masing-masing prediktor dengan kriterium penelitian ini adalah sebagai berikut:

a. Berdasarkan analisis korelasi antara Panjang Tungkai $\left(\mathrm{X}_{1}\right)$ dengan Ketepatan shooting (Y), diperoleh koefisien korelasi sebesar 0.459. Dengan $N=30$, nilai $r_{\text {tabel } 5 \%}=0,361$. Ternyata $r_{\text {hitung }}=0.459>r_{\text {tabel } 5 \%}=$ 0,361. Hal ini menunjukkan bahwa terdapat hubungan yang signifikan antara Panjang Tungkai $\left(\mathrm{X}_{1}\right)$ dengan Ketepatan shooting (Y).

b. Berdasarkan analisis korelasi antara Koordinasi mata kaki $\left(\mathrm{X}_{2}\right)$ dengan Ketepatan shooting (Y), diperoleh koefisien korelasi sebesar 0.423 . Dengan $\mathrm{N}=30$, nilai $\mathrm{r}_{\text {tabel } 5 \%}=0,361$. Ternyata $\mathrm{r}_{\text {hitung }}=0.423>\mathrm{r}_{\text {tabel }} \%=$ 0,361. Hal ini menunjukkan bahwa terdapat hubungan yang signifikan antara Koordinasi mata kaki $\left(\mathrm{X}_{2}\right)$ dengan Ketepatan shooting $(\mathrm{Y})$.

c. Berdasarkan analisis korelasi antara Power otot tungkai $\left(\mathrm{X}_{3}\right)$ dengan Ketepatan shooting (Y), diperoleh koefisien korelasi sebesar 0.403 . Dengan $\mathrm{N}=30$, nilai $\mathrm{r}_{\text {tabel } 5 \%}=0,361$. Ternyata $\mathrm{r}_{\text {hitung }}=0.403<\mathrm{r}_{\text {tabel }} \%=$ 0,361. Hal ini menunjukkan bahwa terdapat hubungan yang signifikan antara Power otot tungkai $\left(\mathrm{X}_{3}\right)$ dengan Ketepatan shooting $(\mathrm{Y})$.

Ringkasan hasil analisis korelasi masing-masing prediktor dengan kriterium penelitian ini adalah sebagai berikut:

Tabel 6. Rangkuman Hasil Analisis Korelasi Tiap Prediktor dengan Kriterium

\begin{tabular}{|c|c|c|c|}
\hline Variabel & $\mathrm{r}_{\text {hitung }}$ & $\mathrm{r}_{\text {tabel }}$ & Simpulan \\
\hline $\mathrm{X}_{1} \mathrm{Y}$ & 0.459 & 0,361 & Korelasi signifikan \\
\hline $\mathrm{X}_{2} \mathrm{Y}$ & 0.423 & 0,361 & Korelasi signifikan \\
\hline $\mathrm{X}_{3} \mathrm{Y}$ & 0.403 & 0,361 & Korelasi signifikan \\
\hline
\end{tabular}

2. Analisis Regresi

Analisis regresi yang dilakukan pada penelitian ini menggunakan analisis regresi ganda tiga prediktor. Hasil analisis regresi antara data tes Power otot tungkai $\left(\mathrm{X}_{1}\right)$, Panjang Tungkai $\left(\mathrm{X}_{2}\right)$, Koordinasi mata kaki $\left(\mathrm{X}_{3}\right)$ Power otot tungkai dengan Ketepatan shooting (Y) penelitian ini adalah sebagai berikut: 
a. Persamaan garis regresinya adalah:

$\hat{\mathrm{y}}=0.095 \mathrm{X} 1+-1.203 \mathrm{X} 2+0.190 \mathrm{X} 3+31.102$

b. Koefisien korelasi dan determinasi antara prediktor dan kriterium:

$\mathrm{R}_{\mathrm{y}(1,2,3)}=0.641$

$\mathrm{R}_{\mathrm{y}(1,2,3)}^{2}=0.411$

c. Uji signifikansi analisis regresi.

Hasil uji signifikansi regresi penelitian ini dapat dilihat pada tabel berikut :

Tabel 7. Ringkasan Hasil Analisis Regresi

\begin{tabular}{|c|c|c|c|c|}
\hline $\begin{array}{c}\text { Sumber } \\
\text { Variasi }\end{array}$ & db & JK & RK & Freg \\
\hline Regresi (reg) & 3 & 2008.7790 & 669.5930 & 6.0494 \\
\hline Residu (res) & 26 & 2877.8877 & 110.6880 & - \\
\hline Total & 29 & 4886.6667 & - & - \\
\hline
\end{tabular}

Dari hasil analisis regresi tersebut dapat disimpulkan, dengan $\mathrm{db}$ $=\mathrm{m}$ lawan $\mathrm{N}-\mathrm{m}-1=3$ lawan 26, harga $\mathrm{F}_{\text {tabel }}$ \% adalah 2,89. Sedangkan nilai $\mathrm{F}$ yang diperoleh adalah 6.0494 , ternyata lebih besar dari angka batas penolakan hipotesa nol. Dengan demikian hipotesa nol ditolak, yang berarti bahwa terdapat hubungan yang signifikan antara Panjang Tungkai $\left(\mathrm{X}_{1}\right)$, Koordinasi mata kaki $\left(\mathrm{X}_{2}\right)$, Power otot tungkai $\left(\mathrm{X}_{3}\right)$ dengan Ketepatan shooting (Y). Adapun besarnya nilai $\mathrm{R}^{2}$ antara Panjang Tungkai $\left(\mathrm{X}_{1}\right)$, Koordinasi mata kaki $\left(\mathrm{X}_{2}\right)$, Power otot tungkai $\left(\mathrm{X}_{3}\right)$ dengan Ketepatan shooting $(\mathrm{Y})$ adalah 0,411.

\section{E. Pengujian Hipotesis dan Pembahasan}

\section{Hubungan Antara Panjang Tungkai dengan Ketepatan shooting}

Dari hasil analisis korelasi pada dataPanjang Tungkai dengan Ketepatan shooting, diperoleh nilai $\mathrm{r}$ sebesar 0.459 , dimana nilai tersebut lebih besar dari nilai $r_{\text {tabel }}$ pada taraf signifikansi $5 \%$ yaitu 0,361 . Karena nilai 
$r_{\text {hitung }}>r_{\text {tabel }}$, maka nilai korelasi signifikan. Hal ini berarti bahwaperubahan variansi Ketepatan shooting dipengaruhi oleh komponen variansi Panjang Tungkai.

\section{Hubungan Antara Koordinasi mata kaki dengan Ketepatan shooting}

Berdasarkan hasil analisis yang telah dilakukan terhadap data Koordinasi mata kaki terhadap Ketepatan shooting, diperoleh nilai r sebesar 0.423 , dimana nilai tersebut lebih besar dari nilai $r_{\text {tabel }}$ pada taraf signifikansi $5 \%$ yaitu 0,361 . Karenanilai $r_{\text {hitung }}>r_{\text {tabel }}$, maka nilai korelasi signifikan. Hal ini berarti bahwa variansi unsur Koordinasi mata kaki berpengaruh terhadap peningkatan variansi Ketepatan shooting. .

\section{Hubungan Antara Power otot tungkai dengan Ketepatan shooting}

Berdasarkan hasil analisis yang telah dilakukan terhadap data Power otot tungkaiterhadap Ketepatan shooting, diperoleh nilai r sebesar 0.403, dimana nilai tersebut lebih besar dari nilai $r_{\text {tabel }}$ pada taraf signifikansi $5 \%$ yaitu 0,361. Karenanilai $r_{\text {hitung }}<r_{\text {tabel}}$, maka nilai korelasi signifikan. Dengan demikian dapat disimpulkan bahwa Power otot tungkai memiliki hubungan yang signifikan terhadap Ketepatan shooting.

4. Hubungan Panjang Tungkai , Koordinasi mata kaki dan Power otot tungkai dengan Ketepatan shooting

Pada Hipotesis dinyatakan bahwa hubungan antara Panjang Tungkai , Koordinasi mata kaki dan Power otot tungkai dengan Ketepatan shooting di ketahui $\mathrm{R}_{\mathrm{y}(123)}^{2}=0.411$ sedangkan $\mathrm{r}_{\text {tabel }}$ pada taraf signifikasi 0,05 dan $\mathrm{n}=30$ di dapat $r_{\text {tabel }}=0,361$, dengan hasil tersebut $r_{\text {hitung }}>r_{\text {tabel5 \% }}$ dan $f_{\text {hitung }}=6.0494$, sedangkan $\mathrm{f}_{\text {tabel5\% }}$ dengan $\mathrm{db} 3: 26=2,89$, ini berarti $\mathrm{F}_{0}>\mathrm{F}_{\text {tabel5\% Maka }}$ hipotesis di terima.

\section{E. SIMPULAN}

Berdasarkan hasil penelitian dan hasil analisis regresi dan korelasi product moment yang telah dilakukan dapat diperoleh simpulan sebagai berikut:

1. Ada hubungan yang signifikan antara Panjang Tungkai dengan Ketepatan shooting, rhitung $=0.459>\operatorname{rtabel} 5 \%=0,361$. 
Hubungan Antara Panjang Tungkai, Koordinasi Mata-Kaki, Dan Power Otot Tungkai Dengan Ketepatan Shooting Sepakbola Pada Pemain Putra Umur 14-15 Tahun Klub Ssb UTP Surakarta Tahun 2020

(Feri Fitrianto)

2. Ada hubungan yang signifikan antara Koordinasi mata kaki dengan Ketepatan shooting, rhitung $=0.423>$ rtabel $5 \%=0,361$.

3. Ada hubungan yang signifikan antara Power otot tungkai dengan Ketepatan shooting , rhitung $=0.403>$ rtabel $5 \%=0,361$.

4. Ada hubungan yang signifikan antara Panjang Tungkai, Koordinasi mata kaki dan Power otot tungkai dengan Ketepatan shooting, R2y(123) sebesar $0.411>$ rtabel5 \% pada taraf signifikansi 5\% sebesar 0.361 dan F0 sebesar $6.0494>$ ftabel pada taraf signifikansi $5 \%$ sebesar 2,89.

\section{DAFTAR PUSTAKA}

Agung Sunarni \& Syifullah D. Sihombing. 2011. Metode Penelitian Keolahragaan. Surakarta Yuma Pusaka.

Agus Mahendra. 2007. Teori Belajar Mengajar Motorik. Bandung: Universitas.

Ali Maksum. 2012. Metodologi Penelitiandalam Olahraga. Surabaya: UnesaUniversity Press

Suharsimi Arikunto. 2007.Prosedur Penelitian. Jakarta:Bumi Aksara.

Udin S. Winata. 2006. Strategi belajar mengajar. Universitas Terbuka. 